\title{
DESIGUALDADE RACIAL NA PRIMEIRA INFÂNCIA
}

\author{
RACIAL INEQUALITY IN EARLY CHILDHOOD
}

\author{
Karen de Almeida Paiva Lamego ${ }^{1}$
}

\section{Isolda Cecilia Bravin ${ }^{2}$}

\begin{abstract}
RESUMO: O presente trabalho tem como tema Desigualdade racial na primeira infância. Onde tem por objetivo discutir o racismo estrutural na educação infantil, partindo do princípio de que a discussão da temática racial ainda na educação infantil, é de grande valia para a integridade na formação do indivíduo. O foco do estudo é de demonstrar que desde a gestação da criança negra e periférica até o ingresso na creche e EDI existe iniquidade. O referido trabalho destacará, leis regulamentadas com a temática de modo a estabelecer reparação histórica para com a população negra, parda e indígena, podem auxiliar o profissional da educação infantil na abordagem em sua prática em sala de aula. Esse tema tão sensível e que conduz muito impacto, quando vivenciado de forma estruturalmente desigual no que diz respeito a diferentes tratamentos, por diferenças em questões raciais e socioeconômicas, podem acarretar desigualdade no processo vivenciando pela criança onde ocorre esse primeiro entendimento de mundo que está presente na educação infantil. É necessário que o profissional da educação infantil tenha conhecimento de como conduzir nessa fase da vida da criança esse assunto que é tão caro para a formação e construção do indivíduo e de toda a sociedade.
\end{abstract}

Palavras- chave: Educação infantil. Primeira infância. Desigualdade racial. Equidade.

ABSTRACT: The present work has the theme of racial inequality in early childhood. Where it aims to discuss structural racism in early childhood education, assuming that the discussion of racial issues in early childhood education is of great value for the integrity in the formation of the individual. The focus of the study is to demonstrate that from the pregnancy of the black and peripheral child to the admission to the day care center and EDI there is inequity. The referred work will highlight, laws regulated with the theme in order to establish historical reparation for the black, brown and indigenous population, can assist the professional of early childhood education in approaching their practice in the classroom. This very sensitive and highly impactful theme, when experienced in a structurally unequal way with regard to different treatments, due to differences in racial and socioeconomic issues, can lead to inequality in the process experiencing by the child where this first understanding of the world occurs in early childhood education. It is necessary that the professional of early childhood education has knowledge of how to conduct at this stage of the child's life this subject that is so expensive for the formation and construction of the individual and the whole society.

Keywords: Early childhood education. Early childhood. Racial inequality. Equity.

\footnotetext{
${ }^{1}$ Estudante de pedagogia, Educadora social na escola Quilombista Dandara dos Palmares, educadora no Movimento infância in Natura, Idealizadora do projeto de musicalização infantilCirandeiras Companhia de artes, pesquisadora da primeira infância Negra e suas especificidades. karen.lamego@yahoo.com.br.

${ }^{2}$ Mestrado em Biotecnologia Vegetal pela Universidade Federal do Rio de Janeiro (200I) e doutorado em Biotecnologia Vegetal pela Universidade Federal do Rio de Janeiro (2005). Atualmente é tutora do Núcleo de Ensino à Distância (NEAD), faz parte da Equipe de Coordenação do Curso de Pedagogia EaD, da Universidade Estácio de Sá, bem como professora de pós-graduação nessa Instituição e pertencente ao Núcleo Docente Estruturante (NDE) dos cursos de Gestão Ambiental e Pedagogia.
} 


\section{INTRODUÇÃO}

Defronte uma sociedade que foi construída tendo por base a escravidão humana, de pessoas negras e indígenas. Se faz necessário a reflexão das consequências desse fato ao longo da história nas práticas educacionais. Principalmente no que diz respeito a educação infantil. Apesar de parecer pouco provável a existência de discriminação racial na educação infantil, é fato que se encontra exatamente nessa conjuntura um ponto de discussão. Nesse contexto sentimos a necessidade de tratar as questões que se relacionam desde a gestação da criança negra em situação de vulnerabilidade até o seu ingresso na educação infantil. A razão disso é contribuir para uma reflexão à luz das práticas educacionais e sociais. O fato é que desde a gestação da mulher negra em situação de vulnerabilidade impacta a criança, tendo em sua maioria como base ambiente violento, precário e em muitas dessas situações com uso de substâncias ilícitas até a chegada da criança na escola com baixa qualidade, promovem um ambiente hostil e desigual de aprendizagem para a criança negra, em situação de vulnerabilidade ainda na primeira infância. Existem diversos estudos realizados pelo Núcleo de ciência e primeira infância que trazem como temática esse assunto.

A educação é um dos fatores que mais influência o nível de bem-estar das pessoas ao longo da vida. Pensar por essa perspectiva é ponderar que o desenvolvimento integral na primeira infância é crucial as experiências ocorridas nessa fase que influenciarão ao longo de toda vida do indivíduo.

Para o desenvolvimento desse trabalho, utilizamos como metodologia a pesquisa de leis, autores que se debruçam em temáticas relacionadas a primeira infância e estudos do desenvolvimento infantil.

O objetivo desde trabalho é mesmo que de forma breve, colaborar para a reflexão da temática de diferença racial na educação infantil e como minimizar os efeitos na mesma.

No referido trabalho é dado ênfase nas evidências que reforçam a importância da educação infantil no desenvolvimento pleno do cidadão. Uma educação antirracista, que contribui com valores éticos e morais que refletem, no bem-estar de toda a sociedade. Outro ponto a ser considerado é um breve resumo da educação infantil no Brasil.

Como forma de embasar as reflexões, da importância da educação infantil no desenvolvimento da criança ao longo dos anos.

Nesse trabalho, é enfatizado as sequelas de uma sociedade pautada no racismo e desigualdades sociais, para a formação comportamental do cidadão. Outro ponto importante a ser estudado, é a desigualdade na qualidade de vida oferecido a criança negra e periférica. A exemplo disso: questões de precariedade no campo da saúde física e emocional. 
É apresentado nesse trabalho, reflexões que ofereça caminhos para tratar a formação de atitudes, posturas e valores nas relações étnicos- raciais. Sopesando que se tratando de educação infantil é preciso pensar estratégias pedagógicas, que tenham no brincar, na ludicidade e contação historias, o seu pilar. Visto que a livre expressão do brincar gera sentido e consciência da realidade para a criança.

I Breve resumo da educação infantil no Brasil

No Brasil, antes do Século XIX, não existiam atendimentos para crianças de o a 6 anos longe da mãe em creches. Uma das instituições brasileiras que passa a atender nesse período é a roda dos expostos como afirma PASCHOAL E MACHADO:

Uma das instituições brasileiras mais duradouras de atendimento à infância, que teve seu início antes da criação das creches, foi a roda dos expostos ou roda dos excluídos. Esse nome provém do dispositivo onde se colocávamos bebês abandonados e era composto por uma forma cilíndrica, dividida ao meio por uma divisória e fixado na janela da instituição ou das casas de Misericórdia. Assim, a criança era colocada no tabuleiro pela mãe ou Qualquer outra pessoa da família; essa, ao girar a roda, puxava uma corda Para avisar a rodeira que um bebê acabava de ser abandonado, retirando-Se do local e preservando sua identidade. (PASCHOAL \& MACHADO, 2009, p. 82)

O primeiro congresso brasileiro de proteção à infância ocorre no ano de 1922 na cidade do Rio de Janeiro. Neste congresso, acontece as primeiras regulamentações que asseguram o atendimento de crianças em idade de primeira infância.

O Congresso representou, no caso brasileiro, a consagração de proposta que vinham sendo desenvolvidas aqui desde o início do século. Objetivo era tratar de todos os assuntos que direta ou indiretamente se referiam à criança, tanto no ponto de vista social, médico, pedagógico e Higiênico, em geral, como particularmente em suas relações com a família, a Sociedade e o Estado. (KUHLMANN Jr, 1999, p. 90 apud MARAFON, s/d, p. 12)

Nesse contexto o congresso foi o momento de trazer as preocupações para as questões das infâncias, visto que se atentar para essa questão é se atentar também para o avanço de toda a sociedade.

Com as evidentes mudanças nos hábitos e formação da instituição família, bem como a inserção da mulher no mercado de trabalho, faz se necessário a observação mais atenta a criação de instituições que ofertam atendimento para a educação infantil. Nos anos de 1970. Essas instituições eram de caráter assistencialista havia pouca preocupação com o desenvolvimento infantil o objetivo dessas instituições era amparar mulheres viúvas e mulheres que trabalhavam fora de casa.

No ano de 1988, a Constituição Federal passou a assegurar, em seu artigo 208, inciso IV, diz que “ $[\ldots]$ o dever do Estado para com a educação será efetivado mediante a garantia de oferta de creches e pré-escolas às crianças de zero a seis anos de idade.” (BRASIL, 1988). 
A constituição de 1988 foi importante para o início das mudanças na educação infantil, foi com ela que a educação infantil passa a fazer parte da educação básica. Assim como aprovação do estatuto da criança e do adolescente-Lei 8.069/9o, no ano de 1990 regularizando o artigo. 227 da constituição federal é inserido a criança e ao adolescente na esfera dos direitos humanos. Como consequência desse momento foi dado um novo olhar para a educação infantil, que não fosse só o de caráter assistencialista. Tendo por base esses fatos e políticas voltadas para a infância podemos perceber as transformações ao longo dos anos, tanto educacionais e sociais. Essas transformações significativas, contribuem para as reflexões que levam às conclusões da importância da educação infantil para a formação da criança.

Entendendo a educação infantil como parte do processo, do desenvolvimento da criança, percebemos a necessidade de fundamenta lá em um conceito de educação para a vida, visto que é na primeira infância que se dará os primeiros recursos cognitivos do desenvolvimento da criança. Nesse sentindo papel fundamental da educação infantil está em garantir o desenvolvimento infantil em todos os aspectos, Como diz a lei de Diretrizes e Bases em seu artigo 29:

A educação infantil, primeira etapa da educação básica, tem como finalidade o desenvolvimento integral da criança de até 5 (cinco) anos, em seus aspectos físico, psicológico, intelectual e social, complementando a ação da família e da comunidade. (Redação dada pela Lei no ${ }^{12.796}$, de 2013)

O processo de vivências sociais legítimas que acontecem na educação infantil, permite a humanização na construção da identidade e subjetividade da criança. Por se tratar da educação infantil é importante mencionar o brincar para além da diversão, mas como sendo parte significativa na construção da saúde emocional da criança, o ato de brincar na educação infantil constitui a vivência de experiências.

As crianças se sentem irresistivelmente atraídas pelos destroços que surgem da construção, do trabalho no jardim ou em casa, da atividade do alfaiate ou do marceneiro. Nestes restos que sobram elas reconhecem o rosto que o mundo das coisas volta exatamente para elas, e só para elas. Nestes restos elas estão menos empenhadas em imitar as obras dos adultos do que em estabelecer entre os mais diferentes materiais, através daquilo que criam em suas brincadeiras, uma nova e incoerente relação. Com isso, as crianças formam seu próprio mundo das coisas mundo pequeno inserido em um maior. (BENJAMIN, 1984, p. 77).

Sendo assim, é na socialização, no livre brincar, na construção subjetiva de mundo que é ofertado na educação infantil que será possível a criança desenvolver habilidades cognitivas, emocionais e sociais ainda na primeira infância. Tomando por base que é na educação infantil que ocorre os processos de desenvolvimento integral do indivíduo, torna- se necessário pensar 
uma educação infantil antirracista. Partindo do princípio que a atual sociedade brasileira foi forjada em estruturas raciais desiguais, temos o entendimento que a educação infantil para crianças negras e periféricas, precisa ser ofertada analisando todas as suas especificidades tais como: o reconhecimento de sua cultura matriz, o reconhecimento de sua etnia de forma valorosa, ambiente acolhedor que auxilie na construção da auto estima enquanto criança negra e periférica. Visto que as crianças não estão em mundo deslocado e são afetadas diretamente, pelos impactos de uma sociedade construída em desigualdade racial e social. As Diretrizes Curriculares Nacionais para a educação infantil em seu artigo 7, inciso V, diz que:

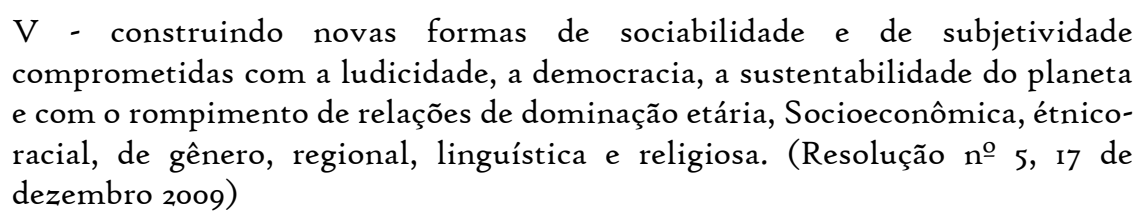
comprometidas com a ludicidade, a democracia, a sustentabilidade do planeta e com o rompimento de relações de dominação etária, Socioeconômica, étnicoracial, de gênero, regional, linguística e religiosa. (Resolução nº 5, i7 de dezembro 2009)

Muito embora existam várias leis regulamentadas que defendem uma educação infantil que assegure direitos básicos a crianças negras, é importante lembrar que em uma perspectiva de mundo se $\mathrm{faz}$ necessário os questionamentos de como as brincadeiras, história, brinquedo elementos que fazem parte a rotina da primeira infância de uma forma geral que oferecidos às crianças negras na educação infantil, reforçam a ideia de supremacia de uma etnia em relação a outra. Nessa conjuntura, dos brancos sobre os negros.

A diversidade e a multiplicidade existem em cada um/a de nós e nos grupos que constituem a humanidade. Estes grupos são fundamentais para a construção de uma nova humanidade, que o trabalho com a educação infantil, com os recém-chegados seres humanos de zero 14 a seis anos, demanda, exige. Uma humanidade sem racismo, que preza o respeito, a convivência e o diálogo. (TRINDADE, 2010, p. I4)

É relevante avaliar que priorizar brincadeiras ou contação de histórias que valorizem a cultura negra, dispõem recursos valorosos para o pedagógico, sob a perspectiva de valorizar a aprendizagem enquanto se constrói a autoestima e aceitação de si mesmo da criança negra. Agregando ainda na primeira infância valores humanos fundamentais como ética e respeito às diversidades. Uma educação infantil antirracista, contribui para a formação de crianças de todas as etnias, avaliando que nesse período de socialização é importante consolidar transformações de preconceitos.

O tema desigualdade racial na educação é um tema caro para a população brasileira. Visto que o Brasil é composto de uma população que em sua maioria é negra. Pensar a educação infantil sob essa perspectiva é um grande desafio principalmente por refletirem as condições na qual a criança negra e periférica chega creche e educação infantil. Quando pensamos a primeira infância e o desenvolvimento pleno da criança, é importante considerar a formação do indivíduo desde a gestação. A gestação da mulher negra e periférica em situação de vulnerabilidade influi 
diretamente na formação cerebral do bebê. Conforme definido por David Willians (2019) os acontecimentos enfrentados pela criança ainda no útero da mãe, podem comprometer as formações biológicas da criança trazendo sequelas que atravessa gerações, porque ocorre transformações no genoma. As chances de crianças negras vivenciarem ambientes precários, desde a gestação fica evidente por compor o grupo da maioria em situação de pobreza.

Com base nessas afirmações podemos refletir as desigualdades raciais enfrentadas, pela criança negra antes mesmo de seu nascimento.

Ora, conhecendo as insuficiências de creches e pré-escolas, públicas e comunitárias, para crianças pobres, pergunto: essa focalização observada não seria decorrência de processo perverso, em razão de essas creches e pré-escolas terem sido criadas, exatamente, para pobres e afugentarem, por sua baixa qualidade, famílias de outros níveis de renda? Sem demagogia, a focalização não decorre de serem "programas pobres para pobres"? Não estaria ocorrendo processo de segregação social ou racial? (BENTO, 2012, p. 37)

A chegada da criança negra periférica na educação infantil é permeada pelas necessidades assistencialistas, que na maioria das vezes é imposta a população negra e periférica. Visto as condições de desigualdades da maioria dos casos, podemos refletir o entendimento da real necessidade desta modalidade de ensino para a criança negra em situação de vulnerabilidade, que não seja apenas para suprir necessidades de cuidados básicos. Ainda que se reflita as questões de desigualdade do ponto de vista social fica evidente que a pobreza afeta ainda mais a criança negra.

Quando todos são pobres, o desempenho escolar da criança negra é inferior ao da branca; a renda da mulher negra é menor do que a da mulher branca, na mesma profissão; o homem negro recebe menos do que o branco, há diferenças na escolaridade etc. Ou seja, a pobreza impacta a criança negra de maneira mais cruel e contundente do que a criança pobre e branca, já que a família negra vive com mais intensidade a desigualdade social. (TRINDADE, 2oro, p. 9I)

Nesse sentido, é relevante observar que os impactos causados pela desigualdade racial sobrepõe o social que se torna necessário uma reflexão aprofundada dos processos pedagógicos que podem minimizar esses impactos, junto à criança negra na educação infantil.

$\mathrm{Na}$ relação da criança pequena com o mundo, as imagens cria referências importantes que será efetivo no processo de construção de auto imagem. Como definido por José Martí (1990) o ato de educar, está associado ao ato de comunicar as outras pessoas, um pouco de tudo que já existiu, até que passe a existir por conta própria. Entendendo que, o referencial imagético é socialmente construído sob os padrões, branco europeu, a criança negra que por vezes não tem a sua auto imagem identificada. Em uma visão global esse fato pode desenvolver a sensação de não pertencimento social.

Para Vigotsky (1984), o psiquismo humano existe por uma apropriação dos modos e códigos sociais. Com a internalização, a criança vai tornando seu o 
que é compartilhado pela cultura; o discurso social passa a ter um sentido individual. Mas os referenciais externos dos negros são dilacerantes. A mensagem transmitida é que, para o negro existir, ele tem de ser branco, ou seja, para se afirmar como pessoa precisa negar o seu corpo e sua cultura, enfim, sua etnicidade. O resultado dessa penalização é o desvirtuamento da identidade individual e coletiva, havendo um silenciamento do preconceito por parte da criança e do cidadão ao longo da vida. (MENEZES 2002, p. 147)

Sendo assim, fica claro que o racismo estrutural na sociedade afeta diretamente a autoestima e a percepção indenitária da criança negra. Afetando diretamente a sua relação e entendimento de mundo. Percorrendo pelo caminho da depreciação da autoimagem.

Não podemos negar que, na construção das sociedades, na forma como negros e brancos são vistos e tratados no Brasil, a raça tem uma operacionalidade na cultura e na vida social. Se ela não tivesse esse peso, as particularidades e características físicas não seriam usadas por nós, para identificar quem é negro e quem é branco no Brasil. E mais, não seriam usadas para discriminar e negar direitos e oportunidades aos negros em nosso país. (GOMES, 2005, p. 48)

Com base nessa afirmação, é importante que se entenda a especificidade da criança negra na construção de sua auto imagem. Especificidade essa que faz com que seu desenvolvimento pleno esteja comprometido quando não assistida com a devida atenção. É preciso que o profissional da educação que lida com a primeira infância, esteja atento às práticas educacionais que auxilia na construção das individualidades, proporcionando um ambiente em sala de aula pautado na educação antirracista.

A lei n.․ 10 639/2003 em seu artigo 27 , inciso $2^{\circ}$ diz que:

§ 2. O Os conteúdos referentes à História e Cultura Afro-Brasileira serão ministrados no âmbito de todo o currículo escolar, em especial nas áreas de Educação Artística e de Literatura e História Brasileiras. (Resolução, 9 de janeiro de 2003)

Sendo assim, fica evidente a necessidade de uma educação igualitária que busca oferecer condições, em que a população negra tenha reconhecido a sua identidade, história e cultura além de assegurar políticas de reparação.

As reflexões que levam a criar movimentos que resultem nas relações étnicos-raciais na educação infantil, é emergir à realidade social que as crianças pequenas vivem. Ponderando as especificidades da primeira infância, as discussões precisam partir do princípio característico dessa fase escolar.

Ao silêncio dos movimentos sociais sobre a educação da criança pequena, se associa um intenso desconhecimento de nós pesquisadores/as sobre as relações raciais que se constroem no âmbito da creche e da pré-escola e da pequena infância. Não raro, preenchemos este desconhecimento por aproximações com o que ocorre nos outros níveis ou etapas da escola, com as crianças maiores. (BENTO, 2012, p. 36) 
Tomando por base tais pressupostos, fica entendido que o ponto de partida é construir uma narrativa pedagógica que considere a subjetividade específica da criança pequena, no que diz respeito ao racismo. Tratando as relações étnicos raciais como cerne dos princípios curriculares.

É necessário, estarmos atentos para o fato de que um dos caminhos que assegurem a equidade nos âmbitos educacionais, é construir desde a educação infantil as questões indenitárias, de forma a contemplar a auto estima da criança negra. Cabe destacar que, a literatura infantojuvenil negra é uma possibilidade nessa construção indenitária. Assim, “o ato de ler e ouvir histórias possibilita à criança expandir seu campo de conhecimento, tanto na língua escrita, quanto na oralidade." (Silva, 2oro, p. 78)

De acordo com essa afirmação, a literatura é importante para o desenvolvimento infantil, logo a literatura infanto -juvenil negra pode contribuir no desdobramento das práticas pedagógicas antirracistas.

Há também os livros que retomam traços e símbolos da cultura afro-brasileira, tais como as religiões de matrizes africanas, a capoeira, a dança e os mecanismos de resistência diante das discriminações, objetivando um estímulo positivo e uma autoestima favorável ao leitor negro e uma possibilidade de representação que permite ao leitor não negro tomar contato com outra face da cultura afro-brasileira que ainda é pouco explorada na escola, nos meios de comunicação, assim como na sociedade em geral. Trata-se de obras que não se prendem ao passado histórico da escravização. (JOVINO 2006, p. 216)

É importante dar ênfase ao fato da importância da qualidade da literatura oferecida à criança, histórias que geram sentindo e identificação. Partindo do princípio de uma literatura que não seja de referencial europeu, de modo a criar estruturas para a auto afirmação da criança negra. Não existe apenas príncipes e princesas do estereótipo que afirmar os traços europeus, uma vez identificado histórias que também as representem, crianças negras passam a ter um novo olhar sobre si mesma.

[...] uma literatura com proposta de representação do negro, que rompa com esses lugares de saber, possa trazer imagens enriquecedoras, pois a beleza das imagens e o negro como protagonista são exemplos favoráveis à construção de uma identidade e uma autoestima. Isto pode desenvolver um orgulho, nos negros, de serem quem são, de sua história, de sua cultura. [...] Investir na construção de uma identidade significa abrir caminho para a revolução no jeito de pensar da sociedade contemporânea, pois os educandos de hoje serão a sociedade de amanhã. A literatura, nesse ínterim, pode ser um espaço de problematização do movimento ocorrido em nossa sociedade. (SILVA, 2010, p. 35)

Nesse sentido, fica claro que o caminho para uma educação infantil de qualidade, que ofereça práticas que garantam a equidade racial é longo. Um dos possíveis recursos para dar início 
a essa trajetória, através da ludicidade, oralidade e o brincar- conceitos caros à primeira infância, é utilizar os recursos contidos na literatura infanto-juvenil negra.

\section{CONSIDERAÇÕES FINAIS}

Considerando, o fato de que as diversidades raciais no Brasil, boa parte se dá em razão do período em que ocorreu a escravização, se torna inviável a desigualdade social e como consequência também no campo educacional a diversidade racial repercute, de modo a criar desigualdade essa que tem início ainda na educação infantil, por isso se faz necessário esse entendimento e as reflexões que possam ajudar a tornar possível, as mudanças que avançaram garantindo a equidade no campo educacional.

Conforme foi citado anteriormente, já se faz presente nas leis brasileiras, como a - Lei n. ํ 10 639/2003 que assegura um ensino de modo a contemplar a cultura afro descente. Tais leis garante para a criança da educação infantil, a oportunidade de construção da identidade Negra, bem como para crianças de outras etnias o reconhecimento dessa cultura, possibilitando desde a primeira etapa da educação básica, o diálogo que favorece as diversidades culturais e étnicas. As Diretrizes curriculares Nacionais da educação em seu artigo, $3^{\circ}$ assegura que:

O currículo da Educação Infantil é concebido como um conjunto de práticas que buscam articular as experiências e os saberes das crianças com os conhecimentos que fazem parte do patrimônio cultural, artístico, ambiental, científico e tecnológico, de modo a promover o desenvolvimento integral de crianças de o a 5 anos de idade. (BRASIL, DCNEI, 2009)

Apoderar-se da concepção proposta no artigo $3^{\circ}$ das Diretrizes Curriculares Nacionais da educação, é garantir uma educação infantil que proporciona compreensão da qual se diz respeito ao legado cultural, que, é construído junto a cultura negra. Partindo do princípio de que existem múltiplos pilares que constituem o processo cultural, como músicas, danças, culinária entre outros que contribuem para expressões individuais que geram reflexos positivos no coletivo.

É relevante, considerar tais reflexões por possibilitar base para a construção desde a educação infantil, uma educação que proporcione ações que não reforcem condutas preconceituosas, visto que tais comportamentos são nocivos às relações humanas. Sendo o objetivo da educação infantil o desenvolvimento integral da criança, é nela que se pode promover o início do caminho para a erradicação do racismo nas estruturas educacionais.

\section{REFERÊNCIAS}

Artigo 27 da lei $\mathrm{n}^{\mathrm{o}} \mathbf{1 0 . 6 3 9 / 2 0 0 3} 9$ de janeiro de 2003. Disponível em: https://www.planalto.gov.br/ccivil_03/leis/2003/lio.639.htm. Acesso em 29 set 2020 
Artigo 29 da Lei $\mathrm{n}^{\circ} 9.394$ de 20 de Dezembro de 1996. Disponível em: https://www.jusbrasil.com.br/topicos/Ir691589/artigo-29-da-lei-n-9394-de-2o-dedezembro-de-1996. Acesso em: 21 set 2020.

BENTO, MARIA APARECIDA. Educação infantil, igualdade racial e diversidade: aspectos políticos, jurídicos, conceituais. Disponível em: http: // portal. mec. gov. br/index. $\quad$ php?option $=$ com_docman\&view $=$ download\&alias $=11283$-educa-infantis conceituais\&category_slug=agosto-2012-pdf\&Itemid=30192 .Acesso em 27 set 2020.

BENJAMIN, Walter. Reflexões: a criança, o brinquedo, a educação. São Paulo, Summus, 1984

Constituição da República Federativa do Brasil: promulgada em 5 de outubro de 1988. Brasília, DF: $1988 . \quad$ Disponível em: 〈http://www.planalto.gov.br/ccivil_03/Constituicao/Constituicao.htm〉. Acesso em: I5 set 2020 .

GOMES, N. L. Alguns termos e conceitos presentes nas relações raciais no Brasil: uma breve discussão. In Secretaria de educação continuada, Alfabetização e Diversidade (SECAD). Educação antirracista: caminhos abertos pela lei federal $\mathrm{n}^{\mathrm{o}}$ ro.639/o3. Brasília: Ministério da Educação, Secretaria de Educação Continuada, Alfabetização e Diversidade (MEC-SECAD), 2005. Disponível em:http://pronacampo.mec.gov.br/images/pdf/bib_volumez_educacao_anti_racista_c aminhos_abertos_pela_lei_federal_ro639_2003.pdf.Acesso em: 29 set 2020.

JOVINO, Ione da Silva. Literatura infanto-juvenil com personagens negros no Brasil. In. SOUZA, Florentina e LIMA, Maria Nazaré (Org.). Literatura Afro-Brasileira. Centro de Estudos Afro- Orientais, Brasília: Fundação Cultural Palmares, 2006.Disponível em:http://biblioteca.clacso.edu.ar/Brasil/ceaoufba/20170829041615/pdf_257.pdf. Acesso em: 30 set 2020 .

LISBOA, Ana Paula." Racismo afeta desigualdade na primeira infância". CorreioBrasiliense.Disponivelem:https://blogs.correiobraziliense.com.br/primeirainf ancia/2019/10/o5/racismo-afeta-desigualdade-na-primeira-infancia-diz-professor-deharvard/. Acesso em 27 de setembro.2020.

MARAFON, Danielle. Educação Infantil no Brasil: um percurso histórico entre as ideias $e$ as políticas públicas para a infância. $\mathrm{S} / \mathrm{d}$. Disponível em: <www.histedbr.fae.unicamp.br/acer_histedbr/.../ZjxYEbbk.doc>. Acesso em :25 ago 2020 .

MENEZES, Valéria. O preconceito racial e suas repercussões na instituição Escola. Recife: Fundação Joaquim Nabuco, 2002. Disponível em:https://meuartigo.brasilescola.uol.com.br/educacao/criancas-negras-umareflexao-sobre-sua-auto-imagem.htm. Acesso em: 28 set 2020 
Ministério da Educação Conselho Nacional de Educação Básica, Resolução № 5, deI7 de dezembro2009.

Disponível em:http://www.seduc.ro.gov.br/portal/legislacao/RESCNE005_2009.pdf. Acesso em: 24 set 2020 .

PASCHOAL, J. D. \& MACHADO, M. C. G. A história da educação infantil no Brasil: avanços, retrocessos e desafios dessa modalidade educacional. Revista HISTEDBR Online, Campinas, n.33, p.78-95, mar.2009. Disponível em: <Http://www.histedbr.fe.unicamp.br/revista/edicoes/33/index.html> acesso em: 24 ago 2020

SILVA, Jerusa Paulino da. A construção da identidade da criança negra: a literatura afro como possibilidade reflexiva. 2010. $78 \mathrm{f}$. Trabalho de Conclusão de Curso (Curso de Pedagogia) - Centro de Ensino Superior de Juiz de Fora, Juiz de Fora. Disponível em:https://www.cesjf.br/revistas/cesrevista/edicoes/20II/I8_PEDAGOGIA_ACons trucao.pdf. Acesso em 30 set 2020.

TRINDADE, Azoilda. A cor da cultura-saberes e fazeres-modos de brincar. Rio de Janeiro, Fundação Roberto Marinho, 2010. Disponível em:http://www.acordacultura.org.br/sites/default/files/kit/MODOSBRINCARWEB-CORRIGIDA.pdf. Acesso em: 26 set 2020 . 